\title{
"A gente parece um camaleão": (re)construções identitárias em um grupo de estudantes cabo-verdianos no Rio de Janeiro
}

Olivia Nogueira Hirsch *

Resumo: $\mathrm{O}$ artigo baseia-se em pesquisa realizada com estudantes provenientes do arquipélago de Cabo Verde, localizado na costa Ocidental da África, que se instalaram no Rio de Janeiro com o objetivo de obter uma formação de nível superior. A investigação, que resultou em uma dissertação de mestrado, busca compreender os processos de (re)construção identitária vividos por esses jovens, muitos dos quais identificados como negros e africanos pelos brasileiros. Com vistas a contextualizar o impacto desse olhar externo sobre esses estudantes, o artigo apresenta a forma como, ao longo da história, a elite intelectual do arquipélago construiu um discurso que atribui à mestiçagem a especificidade da identidade nacional. Ainda que influenciado pelas idéias de Gilberto Freyre, tal discurso, no entanto, visava a um distanciamento da herança negra estigmatizada, diferentemente da proposta de Freyre de valorização dos não-brancos. Levando em conta esse histórico, a investigação aponta como o contato com a sociedade brasileira atual, possibilitado pela experiência de estudo, favoreceu a construção de um olhar mais crítico em relação a esse discurso, ao mesmo tempo que houve uma ênfase na valorização de uma identidade afro-referenciada. Tal processo, entre outros motivos, aparentemente encontra relação com a implementação de políticas de identidade no Rio de Janeiro, estado que abriga a primeira universidade do país a adotar reserva de vagas para negros.

Palavras-chave: estudantes; cabo-verdianos; identidades; deslocamentos; etnicidade.

\section{"We look like chameleons": identity (re)constructions in a group of Cape} Verdean students in $\mathrm{RJ}$

Abstract: The paper is based on a research developed with students from the archipelago of Cape Verde, situated in the west coast of Africa. These students moved to Rio de Janeiro in order to get a college degree. The investigation, which resulted in a master's dissertation, focuses on the identity (re)construction processes experienced by those youngsters, most of whom identified by Brazilians as Blacks and Africans. In an attempt to contextualize the impact of this external categorization over these students, the paper shows how, historically, the Cape Verdean intellectual elite has constructed a speech that considers miscegenation as a national identity specificity. Even though being influenced by Gilberto Freyre's ideas, this speech was intended to dissociate the Cape Verdeans from a stigmatized Black heritage, in opposition to Freyre's intention to valorize non-whites. Considering this background, the

* Professora do Departamento de Sociologia e Política, Pontifícia Universidade Católica do Rio de Janeiro, Brasil. olivianh@gmail.com 
research suggests that the contact with the current Brazilian society, made possible by the study experience, helped them to develop a more critical view regarding this speech, which occurred simultaneously to the valorization of an African identity. For this and other reasons, this process is apparently relatedto the implementation of identity policies in Rio de Janeiro, the first Brazilian state with a university establishing quotas for Black students.

Key words: students; Cape Verdeans; identities; physical mobility; ethnicity.

Durante entrevista nos corredores da Universidade Estadual do Rio de Janeiro (Uerj), primeira instituição de ensino superior do Brasil a reservar vagas para negros e pardos, Feliciana ${ }^{1}$ conta que hoje se sente genuinamente africana. A jovem é proveniente do arquipélago de Cabo Verde, localizado na costa Ocidental da África, a cerca de 500 quilômetros do Senegal. Como ela, outros 300 estudantes cabo-verdianos estão atualmente matriculados em universidades do estado do Rio de Janeiro para obter uma formação de nível superior.

Com idades entre 18 e 29 anos, esses jovens vêm para o país por meio de um programa governamental intitulado Programa Estudante-Convênio de Graduação (PEC-G), firmado pelo governo brasileiro com 43 naçōes da África, do Caribe e da América do Sul. O programa, do qual os principais beneficiários hoje são os estudantes procedentes do arquipélago, oferece gratuitamente vagas em universidades públicas e privadas de várias regiões do Brasil.

Além desse acordo, os cabo-verdianos também são contemplados por outro convênio, firmado diretamente entre a Universidade Santa Úrsula e o Ministério de Educação de Cabo Verde ${ }^{2}$. A universidade, que é privada e se localiza no bairro de Botafogo, Zona Sul da cidade, conta com cerca de 200 estudantes desta nacionalidade em seu quadro discente.

Este artigo, fruto de pesquisa que resultou em uma dissertação de mestrado, busca compreender os processos de (re)construção identitária vividos por esses jovens a partir do contato com a sociedade de acolhida, em especial no que diz respeito à identidade étnica. Ao longo da investigação, realizada entre os anos de 2006 e 2007, foram feitas 30 entrevistas com estudantes no Rio de Janeiro, além de outras seis em Praia, capital de Cabo Verde, com jovens que tinham concluído os estudos no Brasil e retornado ao arquipélago.

Concordando com Abdelmalek Sayad, que afirma que "o imigrante, antes de 'nascer' para a imigração, é primeiro um emigrante” (1998, p. 18) ${ }^{3}$, buscar-

I. Os nomes foram substituídos por outros para preservar a identidade dos entrevistados.

2. Neste caso, os alunos pagam $R \$ 150,00$ mensais para cursar qualquer uma das carreiras oferecidas pela instituição e, assim como no PEC-G, os estudantes ficam isentos do "vestibular".

3. Ainda que os principais sujeitos dessa pesquisa sejam estudantes e não imigrantes, acredita-se que, mesmo nesse caso, tanto a sociedade de origem quanto a de acolhida devem ser, conjuntamente, objeto de reflexão. 
se-á, inicialmente, apresentar alguns aspectos relativos à sociedade de origem que se consideram necessários para a compreensão da experiência desses jovens na sociedade de acolhida.

Nesse sentido, será apresentado o valor atribuído à mobilidade em Cabo Verde - país que possui mais cidadãos residindo no exterior do que dentro de seus limites geográficos -, e abordado o processo de construção da própria identidade nacional cabo-verdiana, que atribui à mestiçagem sua especificidade. Com base nessas informaçôes, em seguida serão apresentados os resultados da pesquisa realizada no Rio de Janeiro, que indicam que uma parcela dos estudantes investigados vivencia um processo de ressignificação das identidades negra e africana durante a experiência de deslocamento, como sugere o relato com o qual se deu início a este artigo.

\section{"Os cabo-verdianos nasceram para o mundo"}

Durante as entrevistas, a grande maioria dos estudantes referiu-se a parentes e conhecidos que se encontravam no exterior. Em conversa com uma informante, ela elencou os vários países em que viviam naquele momento seus familiares: Portugal, Luxemburgo, Estados Unidos e Holanda. E, nesse ponto, essa entrevistada não constitui exceção. Pelo contrário, em Cabo Verde essa é a regra. Não há cabo-verdiano que não tenha um parente no exterior, comentase. Uma piada popular no país é de que, quando o homem foi à Lua, ao chegar lá encontrou um cabo-verdiano.

De fato, a mobilidade é vista pelos nacionais como parte intrínseca da vida. Akesson (2004), que realizou pesquisa de campo no país, aponta a importância atribuída à migração para a constituição do ser cabo-verdiano. "Ter nascido em grãos de areia, como as ilhas são chamadas, no meio do oceano e ter, portanto, que recorrer à emigração, é reconhecido como um predicamento unificador no discurso público" (2004, p.43, tradução livre).

Entre os estudantes, no Brasil, esse discurso também está presente, na medida em que a mobilidade aparece como algo intrínseco: É uma coisa que já faz parte da gente. O cabo-verdiano nasce e ele tem que sair, tem que ir a algum lugar, conta Feliciana. Kátia corrobora: Os cabo-verdianos nasceram para o mundo. Já Paulo define o ilhéu como um emigrante nato, enquanto Pedro comenta que o cabo-verdiano é que nem praga: tá por todo lugar.

Esses relatos, somados a muitos outros, revelam a construção de um mito de identidade internacionalizada, expressão de uma "cultura de migrar para o exterior". Tal termo, elaborado pelo cientista político Wayne Cornelius, "é aplicado para comunidades que têm amplos padrões de migração internacional estabelecidos por longo tempo; muitas crianças esperam ao crescer migrar como 
parte de sua experiência de vida" (Margolis, 1994, p.93-94 apud Assis, 1999, p.130).

O que está em jogo no discurso sobre a migração cabo-verdiana não é apenas a idéia de "destino", amparada pelo histórico de secas e de fomes, mas a idéia de que a mobilidade é uma "especialidade nacional" (Akesson, 2004, p.46), uma atividade especialmente adequada aos "filhos" do arquipélago. A metáfora do camaleão, surgida durante conversa com uma estudante, indica como prevalece no país a representação de que haveria uma "predisposição" do ilhéu à adaptação:

A gente parece um camaleão. É isso que eu falo que o cabo-verdiano é. Aonde a gente vai a gente se adapta na hora, se transforma na cor que for o ambiente. A gente vira natural do ambiente. (Laura, 33 anos, estudou Sociologia, UNB).

Segundo Akesson (2004), essa noção de uma suposta especificidade cultural favorecedora da adaptação é baseada principalmente em duas condições: a imagem de sucesso dos compatriotas espalhados pelo mundo e o histórico crioulo da nação - que será exposto a seguir.

\section{Identidade nacional: entre a Europa e a África}

Colônia portuguesa até 1975, Cabo Verde foi descoberto desabitado nos anos 1460 e povoado por colonizadores europeus e escravos africanos trazidos de diferentes partes da Costa Ocidental do continente. Se num primeiro momento a sociedade se encontrava estratificada, havendo uma correspondência direta entre a hierarquia de posições sociais e a origem étnica, no fim do século XIX esse cenário começava a passar por um processo de transformação.

Como aponta Anjos (2002), a dependência dos proprietários de terra aos movimentos do mercado, os efeitos da seca ${ }^{4}$ e a partilha de bens entre os herdeiros contribuíram para minar os recursos que mantinham a elite branca no topo da hierarquia, o que ocorreu concomitantemente à gradativa ascensão de não-brancos por meio da educação e da emigraçãos.

4. As secas marcaram toda a história do arquipélago. Quando em condições normais, o curto ciclo de chuvas é de aproximadamente 90 dias no ano, com uma média anual de precipitação de apenas $250 \mathrm{~mm}-300 \mathrm{~mm}$. Das prolongadas e freqüentes estiagens que assolaram o arquipélago ao longo de sua história, combinadas com o progressivo aumento da população e da erosão do solo, resultaram fomes e altas taxas de mortalidade. Segundo Carreira (1977), nos chamados "anos de crise" chegaram a morrer até $30 \%$ da população.

5. Neste caso, isso se dava através do envio de remessas ou por meio do retorno para restabelecimento na terra de origem com a poupança adquirida no exterior. 
Desde muito cedo no arquipélago a instrução da população ficou a cargo da Igreja, que atuou como uma espécie de transmissora dos valores ocidentais. Esse fato, observa Fernandes (2002), contribuiu para que a ascensão social dos negros não fosse acompanhada de uma valorização de sua cultura, mas, ao contrário, de uma tentativa de ocultação do passado escravista. Assim, afirma o autor, "quanto mais negros chegavam ao pólo dominante da estrutura social cabo-verdiana, mais branca se tornava a sociedade" (Fernandes, 2002, p. 220, grifo do autor).

A instauração da República em Portugal (em 1910) institucionalizou o sistema de ensino, que passou a ter como orientação a divulgação dos pressupostos nacionalistas e, conseqüentemente, o "aportuguesamento" da população nas colônias. Em Cabo Verde, tal operação foi bem recebida, pois a percepção local era de que a assimilação cultural facilitaria o branqueamento social e a mobilidade vertical. A luta por afirmação na ordem hierárquica, antes baseada na ascendência ou naturalidade portuguesa, dava lugar então à partilha de uma cultura comum, moldada e disseminada pela educação. Assim, fosse através dos laços biológicos ou culturais, a constante busca era por um afastamento em relação à herança negra, estigmatizada, que Fernandes (2002) comparou a uma espécie de "má-formação congênita", a qual se tentava "extirpar".

Foi nesse contexto que começou a se conformar no arquipélago uma elite letrada, que viria a substituir os antigos proprietários de terra na mediação com as autoridades coloniais. Tal elite, fundamental para a divulgação dos valores da metrópole no arquipélago, encontrava sua origem social "no ponto de encontro de dois grupos sociais em trajetórias inversas” (Anjos, 2002, p. 52): aquele composto por não-brancos, que por meio da emigração e da educação se encontrava em processo de ascensão, e o proveniente de famílias brancas decadentes, que investiam na educação para tentar conquistar cargos intermediários do funcionalismo. Em nome da crença no compartilhamento de uma cultura comum com a metrópole - e a percepção de que de fato havia um distanciamento em relação às demais colônias da África -,essa nova elite se dispôs a auxiliar Portugal na tarefa de "civilizar" os nativos. Assim, passou a exercer cargos intermediários na administração colonial em Angola, Moçambique, São Tomé e Guiné Bissau, atendendo aos interesses da metrópole, que vinha sendo pressionada a ocupar efetivamente "seus" territórios.

Mas, ao mesmo tempo que eram catapultados à condição de "segundo colonizador", os cabo-verdianos, em meio às constantes secas que assolavam o arquipélago, também eram enviados a realizar trabalhos forçados nas plantações de café e cacau de São Tomé e Príncipe. Lobban (1995) resume bem esse intrincado cenário no qual estavam imersos os ilhéus. Na definição do autor, eles foram "simultaneously subordinated and elevated. Historically, Cape 
Verdeans had been both slaves and slavers; consequently, they were both victims and victimizers in the colonial structure" (1995, p.58).

Esse fato, somado a outras frustradas reivindicações dos ilhéus, que aspiravam a receber um tratamento diferenciado por parte da metrópole, levou a elite local a ensaiar um "resgate do potencial identitário africano" (Fernandes, 2002, p. 73). Isso implicou uma releitura da cultura popular, que ganhou destaque e passou a ser valorizada pelos chamados "nativistas" - como foram batizados os integrantes do movimento, fortemente influenciado pelo Modernismo brasileiro.

No entanto, com a implantação do Estado Novo em Portugal ${ }^{6}$, no início da década de 1930, esse cenário voltou a sofrer mudanças. O novo regime passou a reprimir qualquer tipo de manifestação e intensificou a divulgação da ideologia assimilacionista, como parte de um processo de afirmação e expansão da própria nação portuguesa ${ }^{7}$.

Nesse contexto, mais precisamente no ano de 1936, foi fundada a revista Claridade, "tendo se constituído num dos principais instrumentos de articulação e publicização das novas orientações político-culturais da intelectualidade cabo-verdiana" (Fernandes, 2002, p. 79). Criada por um grupo de jovens, a revista atuou como espaço de construção da cabo-verdianidade. Mas ao mesmo tempo que buscava exaltar os valores próprios de uma identidade local, de modo a garantir o reconhecimento da população do arquipélago, reafirmava a aproximação cultural com a metrópole. Isto era possível na medida em que a África, percebida como "exótica" e "longínqua", despontava como referência de contraste.

Assim, aponta Fernandes (2002), a cultura local foi reinventada de forma a equiparar o mestiço ao europeu, novamente omitindo as manifestaçóes que não coincidiam com esta representação. $\mathrm{Na}$ realidade, os traços africanos da cultura eram reconhecidos, porém, vistos apenas como resquícios, fadados ao desaparecimento. Assim, a mestiçagem converteu-se em uma espécie de síntese bem-sucedida, representando a absorção do que de melhor havia tanto em aspectos culturais quanto "raciais". Tal representação foi disseminada pelos "claridosos" e absorvida pelo imaginário social sem grandes resistências.

Deve-se chamar atenção para a grande influência das obras de Gilberto Freyre, cujas análises vinham sendo disseminadas exaustivamente pelo poder colonial e apropriadas pelos intelectuais do arquipélago. De fato, observa Thomaz (1996), isso se deve a um "diálogo implícito" do autor brasileiro com a

\footnotetext{
6. Regime ditatorial liderado por António Salazar, que vigorou sem interrupção em Portugal de 1933 até 1974.

7. Para mais informações sobre esta questão, ver Thomaz (1996).
} 
intelectualidade colonialista durante as primeiras décadas do Estado Novo português, o que contribuiu para uma universalização da teoria gilbertiana, inicialmente limitada ao contexto brasileiro.

A influência das reflexôes de Freyre acerca da mestiçagem no Brasil, contidas no clássico Casa Grande \& Senzala, foi de tal monta no arquipélago que os claridosos, apropriando-se delas, chegaram inclusive a concluir que Cabo Verde seria possivelmente o melhor exemplo - melhor ainda que o Brasil - da integração portuguesa nos trópicos. Isso porque argumentavam que, no arquipélago, a integração étnica se deu "totalmente", o que convertia a sociedade cabo-verdiana em uma aproximação praticamente fiel do tipo ideal de integração “multirracial” sugerido por Freyre (Almada, 1992).

No entanto, apesar de chegar a resultados semelhantes, as idéias sobre mestiçagem no Brasil e em Cabo Verde parecem ter percorrido caminhos bastante distintos. Enquanto em terras brasileiras Freyre buscava exaltar o mestiço como uma forma de se contrapor à ideologia do branqueamento que servia de sustentação à construção da identidade nacional, em Cabo Verde a intelectualidade buscava fazer justamente o inverso. A mestiçagem era valorizada como uma possibilidade de se demonstrar à metrópole portuguesa que havia um afastamento em relação à negritude e à África, ou seja, o discurso sobre a mestiçagem tinha como objetivo "embranquecer" a população e não se opor a esse tipo de olhar, como propunha o intelectual brasileiro (Anjos, 2000).

Assim, a idéia de uma mestiçagem percebida como positiva é apropriada em Cabo Verde, mas o mestiço cabo-verdiano, ainda que promovido a ponto central da identidade nacional, é visto como inserido em um processo evolutivo, do qual faz parte a eliminação do componente cultural africano. Um dos principais expoentes claridosos, Baltasar Lopes, chega a afirmar que "nós estamos muito mais aproximados do tipo português de cultura do que talvez suponhamos" (Lopes, 1957, p. 07). Isso porque, como sugere Fernandes (2002), a imagem construída era de que o que havia de genuinamente cabo-verdiano não chegava a diluir sua lusitanidade. Ao mesmo tempo, processo inverso ocorria em relação aos traços culturais herdados do continente africano. Hernandez (2002) corrobora essa visão, afirmando que a interpenetração de culturas está longe de ser um processo igualitário. Levando esse aspecto em consideração, a autora aponta o papel do mulato no arquipélago:

É compreensível que o mulato de negatividade seja transformado numa positividade que representa uma categoria que apreende a própria identidade nacional. Deve-se, porém, ter claras as implicações decorrentes da ambigüidade do mito da mestiçagem que promove uma perda em termos da especificidade da cultura negra, além de encobrir as inúmeras 
dificuldades concretas para que ela possa realizar-se (Hernandez, 2002, p. 99).

Dessa forma, ocultando as especificidades da "cultura negra", como aponta a autora, o discurso dos claridosos atendia aos interesses da metrópole. No entanto, como ocorrera com os nativistas, as demandas dos claridosos intensificaram-se, sendo a principal delas a reivindicação de um estatuto diferenciado para Cabo Verde. Mas, se a aproximação com a metrópole era suficiente para que cabo-verdianos assumissem o papel de civilizadores das demais colônias africanas, o mesmo não se pode dizer quando a questão se referia a obter estatuto semelhante ao concedido às ilhas européias de Açores e Madeira.

Esse cenário sofreu importante reviravolta com a nova conjuntura internacional que se configurava na década de 1950, período em que a identidade nacional foi acompanhada de uma valorização do que entendiam ser a cultura africana, nesse momento convertida em mobilização política. A mestiçagem cabo-verdiana, anuladora de uma de suas supostas partes constitutivas, passava a não mais fazer sentido. Ganhava então proeminência a "geração de 1950", que buscava na plasticidade da identidade cabo-verdiana recuperar os traços de "africanidade" necessários ao movimento pela independência, presente nas demais colônias do continente. O manifesto redigido em 1962 por Manuel Duarte, intelectual dessa geração, é um exemplo desse processo:

Nós, Povo das Ilhas, não queremos continuar a pensar com pensamentos que não nos pertencem e nos foram impostos pela dominação colonial portuguesa; não queremos continuar a sentir com os sentimentos que nos são alheios e nos constrangem a renegar o nosso corpo (nossa cor, nosso nariz, nossos cabelos...) e a grande raça negra materna. Queremos cultivar o nosso próprio ideal de beleza na criatura humana, na natureza, na vida. Eis por que (e por dizer muito fica nossa experiência fundamental com o sofrimento) estamos decididos a quebrar as cadeias do jugo colonial e escolhemos livremente nosso destino africano (Duarte, 1999, p. 37).

A referência à identidade portuguesa cai em desuso e Cabo Verde recorre à Guiné-Bissau para "provar" a legitimidade de sua "africanidade" e da reivindicação por independência. Assim como ocorrera em relação a Portugal, houve uma exacerbação das semelhanças e um concomitante ocultamento das diferenças com o vizinho continental africano. Tal estratégia funcionou na medida em que lutavam contra um inimigo comum. No entanto, a intensificação dos combates e a aproximação da vitória, em vez de reforçar os laços de solidariedade entre Guiné-Bissau e Cabo Verde, geraram uma inflexão do projeto comum e da mobilização identitária. 
Com a independência e o inevitável fim da unidade entre os dois países, assistiu-se a uma reabilitação do discurso da "cabo-verdianidade", que passou a conviver com contribuiçôes da "africanidade". Contudo, uma nova reviravolta pôde ser observada após a primeira eleição pluripartidária no país, realizada em 1991, logo depois da queda da União Soviética e da inauguração de uma nova ordem mundial. O partido vitorioso foi o oposicionista Movimento para a Democracia (MPD), que retomou a parceria estratégica com a ex-metrópole. Provavelmente um reflexo desse cenário, vem sendo debatida no país uma possível adesão do arquipélago à União Européia (UE). Um primeiro passo nesse sentido foi dado em novembro de 2007, ocasião em que se chegou a um acordo durante reuniáo em Bruxelas, que previu uma futura "parceria especial" de Cabo Verde com a UE.

Como foi possível notar, durante a maior parte de sua história, Cabo Verde buscou exaltar as semelhanças culturais e identitárias com Portugal, processo que foi acompanhado de um distanciamento em relação à África e aos africanos. Ainda que essa construção tenha atendido principalmente a motivações políticas, que visavam trazer benefícios a uma minoria, essa representação de uma identidade cabo-verdiana plástica e mestiça passou a fazer parte do imaginário nacional. Não à toa, muitos rejeitam até hoje a associação com o continente, sobre o qual recai o pesado estigma de "atraso" e "incivilidade".

\section{Cabo-verdianos no Rio de Janeiro}

É de uma sociedade com esse histórico, isto é, de valorização da mestiçagem como possibilidade de afastamento de uma herança negra e estigmatizada, de onde partem os jovens que são objeto desta pesquisa. No entanto, durante as entrevistas realizadas ao longo da investigação, chamou atenção o fato de que a maior parte dos estudantes (63\%), ao ser indagada sobre sua classificação racial, optou por identificar-se como "negro" e, não raro, também como "africano".

Na prática, o que se observou foi que, durante a experiência de deslocamento, as identidades negra e africana foram ressignificadas por muitos desses jovens, em um processo que em geral veio acompanhado de mudanças de comportamentos e de atitudes, bem como da exibição pública de atributos associados à negritude, como roupas e cabelo.

Vale destacar que, dependendo do contexto no qual estão inseridos, os estudantes recorrem a diferentes símbolos da cultura negra. Nesse sentido, se em determinados momentos a referência predominante é a uma África tradicional, que passam a valorizar no Brasil, noutras é a uma África que toma como inspiração símbolos da cultura negra internacional, o que se poderia elaborar como um reflexo do "sentimento de pertencimento a uma comunidade mais ampla: os negros da diáspora" (Giacomini, 2006, p. 203). 
Tal diferença pôde ser observada nos diferentes eventos organizados pelos estudantes. Enquanto nos convívios ${ }^{8}$, realizados durante o dia, foi possível localizar uma associação com uma África tradicional, com jovens trajando bubus, roupas djila ${ }^{9}$, camisetas com o rosto de Amílcar Cabral ${ }^{10}$ - ainda que não estivessem excluídas camisetas de basquete americano ou com as cores associadas ao reggae - durante as festas realizadas à noite o clima era muito distinto, principalmente entre as mulheres. A referência nesse momento era, em grande medida, o hip hop americano e a moda seguia aquela ditada pelos clipes gravados para divulgar as canções.

Sobre essa questão, Sansone (2004) aponta que certas interpretações de negritude podem assumir um toque de nostalgia, buscando-se um reencontro com um passado mítico, para o qual se recorre a referências ao continente africano ou à escravidão, por exemplo. Pinho (2004) observa que em países onde há grande presença de afro-descendentes é comum a idealização de uma "África" mítica, percebida como "genuína" e vista como um todo indivisível. Por outro lado, outras interpretações servem principalmente como um instrumento para conquistar acesso à "modernidade" e, em geral, tomam como referência o negro dos Estados Unidos, visto como tendo um alto poder aquisitivo e político.

Além do vestuário, foi possível observar a incorporação de outros atributos associados à negritude por parte dos jovens pesquisados. Assim, no que diz respeito ao cabelo, quase todos o usavam crespo, solto ou com tranças, ou mesmo com dreadlocks. Sobre essa questão, vale destacar que alguns revelaram que passaram a adotar tal prática depois de terem se estabelecido na cidade ${ }^{11}$. $\mathrm{O}$ que ficou claro é que um número significativo de estudantes tentou exprimir em seus corpos símbolos que remetiam a uma representação de africanidade, em grande medida construída aqui ${ }^{12}$.

8. "Convívio" ou "chintada" é o nome dado a encontros informais de amigos, que se reúnem para conversar, comer a tradicional cachupa, além de jogar cartas e uril, muito popular no arquipélago.

9. Palavra que quer dizer "comerciante ambulante", mas que em Cabo Verde foi atribuída ao próprio traje, que é trazido do Senegal.

10. Considerado o herói da independência de Cabo Verde.

I I. Nesse sentido, é interessante notar que, de acordo com Handing (200 I), processo bastante diverso teve lugar no grupo de estudantes cabo-verdianas que pesquisou na cidade do Porto, em Portugal. A autora aponta em sua tese como nenhuma das jovens de Cabo Verde com as quais manteve contato durante a pesquisa usava penteados "afro" e que as que tinham o cabelo mais liso eram, em geral, alvo de admiração das demais. Durante o trabalho de campo, Handing morou em uma república com estudantes cabo-verdianas e observou que as jovens passavam horas "alisando" o cabelo umas das outras. Além disso, uma delas chegou a Ihe confidenciar que seu cabelo, menos crespo que o das demais, era considerado o "orgulho da família".

12. A maioria dos entrevistados nunca esteve no continente africano e alguns chegaram a comentar que o Brasil é "mais África" do que Cabo Verde. Por outro lado, muitos estudantes já estiveram em países da Europa ou nos Estados Unidos. 
A experiência desses jovens leva-nos a refletir sobre como o corpo, assim como qualquer outra realidade, é socialmente construído. As normas corporais são desde muito cedo aprendidas e as pessoas sequer se dão conta de que são resultado da cultura, e não da biologia. A aparente contradição reside no fato de que o corpo é encarado como "natural" e "universal" pelos sujeitos, mas as influências sociais que comporta não escapam a um olhar um pouco mais atento. Nesse sentido, destaca Rodrigues (1979), os corpos são afetados pela religião, pela ocupação profissional, pela classe social, pelo grupo familiar, etc. Em outras palavras, o corpo revela-se como o lugar primordial da(s) identidade(s), sendo influenciado pelos distintos contextos com os quais dialoga e, ao mesmo tempo, convertendo-se em meio de afirmação pessoal.

Segundo Le Breton, na pós-modernidade o "corpo torna-se o emblema do self. A interioridade do sujeito é um constante esforço de exterioridade" (Le Breton, 2003, p. 29). Assim, observa o mesmo autor, o corpo e a aparência, isto é, a maneira de se apresentar socialmente, convertem-se em uma espécie de "cartão de visitas vivo" (Le Breton, 2007, p. 78), que busca orientar o olhar do outro sobre si. Tal processo é compreensível na medida em que a identidade - expressa na corporalidade - é resultado de uma relação. Portanto, se a forma como o "outro" enxerga é determinante para que o sujeito se defina, é natural que este busque orientar esse olhar externo para evitar que seja, como sempre se está passível, classificado à revelia. E, na medida em que o "outro" é passível de variação, isto é, a relação pode ser estabelecida em circunstâncias e contextos sociais distintos, como ocorre nas situaçôes de "migração, exílio e viagem", tal qual observa Le Breton (2007, p. 65), o corpo passa também por um processo de reelaboração e adaptação.

Ao longo da pesquisa, e com base nas entrevistas, foi possível mapear alguns fatores que aparentemente contribuíram para esse processo de ressignificação das identidades negra e africana por parte desses jovens. Em primeiro lugar, deve-se destacar que, no Brasil, de maneira geral, e no Rio de Janeiro, em particular, há atualmente uma grande visibilidade do tema "raça".

Esse movimento teve início nos anos 1990, ocasião em que a questão "racial" ganhou significativa atenção institucional no país. Segundo Fry (2005), a influência de estudiosos americanos, de um movimento negro articulado, aliado a pesquisadores e ONGs, foi fundamental para que várias medidas relacionadas à população negra fossem incluídas na reforma constitucional de 1988. Nesse sentido, o documento previu pesadas penas para quem cometesse atos de racismo, propôs um amplo reconhecimento da cultura negra - com especial atenção à religião -, estabeleceu a implementação de conselhos consultivos dos quais participavam membros de organizaçōes negras, além do reconhecimento dos direitos de propriedade aos descendentes de quilombos. 
A atenção dada à questão "racial" nesse momento foi um passo decisivo para a implementação de políticas de identidade, como é o caso das políticas de ação afirmativa, que representam uma ruptura com a tradição universalista do país. Cabe ressaltar que, tendo o estado abrigado a primeira universidade do país a aderir à política de reserva de vagas para negros, o debate sobre o tema pôde ser acompanhado diariamente na imprensa local.

Esse cenário, aparentemente, vem contribuindo para a valorização de uma identidade afro-referenciada. Isto é, as representaçōes negativas associadas ao negro, que ainda encontram eco em vários segmentos da sociedade, aparentemente vêm sendo transformadas por imagens positivas, como sugere o aumento do número de negros na última Pesquisa Nacional por Amostra de Domicílios (Pnad). De acordo com a sondagem, a parcela da população que mais cresceu em 2006 foi a de negros (1,345 milhão), ao mesmo tempo que se registrou uma aproximada redução do número de pardos. Segundo analistas citados pela imprensa, os dados levam a crer que aqueles que antes se identificavam como pardos passaram a se declarar negros.

Um fator que parece ter influenciado os estudantes cabo-verdianos durante a estadia aqui ? também como parte desse processo ? foi o fato de, no círculo universitário no qual esses jovens estão inseridos, predominar classificações "raciais"/de cor do tipo bipolar, isto é, que divide o sistema em apenas duas categorias: brancos e negros (Fry, 2005). Para o autor, o privilegiamento deste tipo de classificação está associado à presença de uma classe média intelectualizada e urbana nesses ambientes.

Outro aspecto relevante para a compreensão do processo de ressignificação identitária vivenciado por parte desses jovens é o fato de que, como a maioria dos brasileiros desconhece o arquipélago, muitos deles se vêem obrigados a localizar geograficamente o país de origem. A informação, dada repetidas vezes, de que Cabo Verde se encontra na costa da África acaba por gerar um impacto nos próprios estudantes, ao mesmo tempo que promove uma expectativa, principalmente entre seus pares no meio universitário, no que diz respeito a suas atitudes e posicionamentos em relação à negritude.

Essa nossa miscigenação, de ter uma cor intermédia, criou uma espécie de falta de identificação, de identidade, então quando eu cheguei no Brasil eu tive que falar para todo mundo que eu era africano e isso de certa forma produziu um efeito em mim. Eu deixei o cabelo crescer e eu fiquei me sentindo muunito (sic) mais africano do que eu me sentia antes de ir para o Brasil. (Austelino, 32, Administração, estudou na Universidade Federal de Viçosa). Obrigatoriamente, quando eu cheguei aqui, eu tenho que falar que sou africana, porque é a unica referência que eu posso dar para eles, 
éo que mais próximo eu posso explicar. Eu tenho que falar que meu país fica na África ou que fica perto de África. Eu tenho que automaticamente me identificar com a África para me localizar, para me identificar. [...] claro que quando eu falo assim, eu tento buscar também o que tem de africano no meu pais para passar (Evandra, 21 anos, Arquitetura, UFRRJ).

Eu acho que eu fiquei me sentindo [mais africana], porque as pessoas perguntam: 'Você é de onde? Eu sou africana'. Em Cabo Verde eu nunca diria que eu sou africana. Aqui eu passei a me identificar mais como africana. Eu falo que eu sou africana o tempo todo.

Pergunta: E se apresentar dessa forma gerou um reforço na sua identidade?

É, é isso que aconteceu. É verdade, é isso! (Eunice, 27 anos, Biomedicina, Uni-Rio).

No entanto, como sugerem os relatos acima, muitas vezes essas identidades só ganham sentido para esses jovens fora da sociedade de origem. Isso porque a identidade étnica se constrói de forma contextual e na relação com outras identidades sociais, sendo sempre negociada, de modo que a visão externa co-determina a forma como o próprio grupo étnico se (re)constrói. Jenkins (1997) define este como sendo um processo dialético, no qual definiçōes internas e externas estão mutuamente implicadas.

Outro dado que não deve ser desprezado na análise é o maior contato que esses jovens têm com estudantes de outros países da África, principalmente no caso dos que moram na Zona Norte da cidade. No arquipélago, esse contato é quase sempre marcado por uma relação desigual em termos de classe social. Isto porque, em Cabo Verde, a maioria dos africanos do continente que lá se encontra é composta por imigrantes que se dedicam à construção civil e ao comércio ambulante, sendo altamente estigmatizados. No Brasil, no entanto, são todos igualmente estudantes e vistos pela sociedade abrangente também como igualmente "africanos".

Pergunta: Você acha que ter saído de Cabo Verde reforçou a sua identidade africana?

Eu acho que sim. Como que isso reforça a minha identidade? Pelo simples fato de eu conviver com outros africanos, certo? Conviver com africanos que reconhecem que são africanos e negros, né? $E$ conviver com essas pessoas vocêse sente numa turma onde as pessoas estão de uma forma ou de outra tendo oportunidade, né? (Ênio, 25 anos, Pós-graduação Engenharia de Telecomunicaçōes, UFF).

Por fim, também relevante nesse processo parece ser a constatação, por uma parcela dos estudantes, de que é alvo de preconceito e discriminaçăo "racial" na 
sociedade brasileira. Em Cabo Verde esse tema não costuma ser objeto de reflexão, pois a população, de maneira geral, considera que não existe racismo no país, já que todos são percebidos, ao menos idealmente, como "igualmente mestiços" ${ }^{13}$.

Nesse sentido, muitos entrevistados se disseram surpresos com a discriminação "racial" encontrada aqui. A imagem que tinham do Brasil era uma mescla entre "o Brasil das novelas" ${ }^{4}$, isto é, um país de belas paisagens, praias, pessoas bonitas e bem vestidas, e "o Brasil do Cidade Alerta". Mas mesmo nesse programa, exibido pela TV Record e que apresenta uma imagem bastante negativa do país, ao tratar de forma sensacionalista o tema da violência, essa questão não é abordada.

Contudo, se a discriminação na sociedade de acolhida é algo que os estudantes cabo-verdianos desconheciam, para os rapazes, no entanto, ela é rapidamente constatada. Eles se vêem freqüentemente sendo alvos de blitz da polícia, em especial aqueles que moram no bairro Maracanã, próximo à Uerj. Com efeito, vários foram os depoimentos de jovens que disseram ter sido abordados por policiais armados em ônibus, táxis ou mesmo a pé.

Já as cabo-verdianas não costumam se ver envolvidas nesse tipo de situação; aliás, os rapazes observam que a presença delas evita que sejam abordados por policiais. Para elas, as maiores reclamaçōes vêm das experiências vividas em shoppings e centros comerciais, onde não costumam receber o tratamento esperado por parte das atendentes. Em relação a esses ambientes, nos depoimentos dos rapazes há queixas sobre o comportamento de seguranças - que costumam segui-los nas lojas -, além de constrangimentos no momento de pagar a compra, quando são solicitados documentos adicionais, o que verificam não ocorrer com os demais clientes. O impacto provocado por essas experiências aparentemente acaba influenciando a percepção que esses jovens têm sobre si, como sugerem os relatos abaixo:

Acho que todo mundo que vem aqui para o Brasil, vaipara Cabo Verde se sentindo africano, tem essa história do negro e do afro aqui no Brasil e a gente sente muito isso na pele, eu sinto, eu fico com raiva quando eu vejo cenas de racismo (Lina, 27 anos, Pós-Graduação Serviço Social, UFF).

Antes de vir eu não me achava como uma africana nata, pura, eu diria, eu sou cabo-verdiana, mestiça, mistura de povo africanos e europeus, não sou uma africana pura. Todo cabo-verdiano sente isso. Mas aqui hoje eu me sinto africana, genuinamente africana.

13. Para uma discussão mais aprofundada dessa questão, ver Hirsch (2007).

14. As telenovelas brasileiras, exibidas em horário nobre, são sucesso de audiência em Cabo Verde. 
Aqui eu consegui encontrar minha identidade, devido a todas as questôes raciais que eu vi eu consegui me localizar (Feliciana, 26 anos, Pós-Graduação Psicologia Social, Uerj).

Em suma, a experiência de "sentir na pele" a discriminação ou de depararse com questões raciais que ainda não tinham sido objeto de reflexão parece também contribuir para esse processo mais amplo de ressignificação das identidades negra e africana por parte do grupo pesquisado.

\section{Considerações finais}

Com base no que foi exposto, sugere-se pensar a experiência dos estudantes cabo-verdianos no Rio de Janeiro como um interessante "espelho onde nossa própria existência se reflete" (DaMatta, 2000). Isto é, como um reflexo da própria sociedade atual, em que o tema "raça" adquiriu grande visibilidade, em meio ao debate gerado pela implementação de reservas de vagas para negros em universidades públicas, à obrigatoriedade do ensino de história da África e ao reconhecimento do direito de propriedade a remanescentes de quilombos, entre outros temas.

Considerando que uma das singularidades da experiência desses jovens é a expectativa de retorno ao país de origem após a conclusão do curso universitário, revela-se oportuna também uma reflexão sobre o possível impacto do processo de (re)construção identitária vivenciado aqui por ocasião do regresso a Cabo Verde. Nesse sentido, sugere-se que duas hipóteses possam ser, inicialmente, traçadas.

Levando em conta que esses jovens vão futuramente conformar a elite intelectual cabo-verdiana (em um país em que, segundo o Censo 2000, apenas $1,1 \%$ da população possui nível superior), a primeira possibilidade que se deve cogitar é a de que, ao retornarem, esses estudantes convertam-se nos protagonistas de um novo discurso sobre a identidade nacional cabo-verdiana, que inclua também as contribuiçôes negras e africanas àquela sociedade.

No entanto, outra possibilidade que não deve ser descartada é a de que, ao identificarem-se como negros e africanos no Rio de Janeiro, esses jovens estejam, na prática, reforçando a híbrida e plástica identidade cabo-verdiana, que tantas oscilações sofreu ao longo da história. Nesse sentido, cabe questionar até que ponto esses estudantes estão negros e africanos aqui. Se esse for o caso, é válido pensar que, enquanto constroem um olhar crítico sobre a mestiçagem e a identidade cabo-verdiana, esses jovens estão, por outro lado, reafirmando a plasticidade que lhes é constitutiva. A gente parece um camaleão, comparou uma entrevistada, acrescentando sugestivamente: se transforma na cor que for $o$ ambiente. 


\section{Referências bibliográficas}

AKESSON, Lisa. Making a life: meanings of migration in Cape Verde. 2004. Tese (Doutorado) — Departamento de Antropologia Social, Göteborg University, Suécia.

ALMADA, David Hopffer. Caboverdianidade e tropicalismo. Recife: Massangana, 1992.

ANJOS, José Carlos Gomes dos. Cabo Verde e a importação do ideologema brasileiro da mestiçagem. Horizontes Antropológicos, Porto Alegre, ano 6, n 14, p. 177-204, novembro de 2000 .

ANJOS, José Carlos Gomes dos. Intelectuais, literatura epoder em Cabo Verde: lutas de definição da identidade nacional. Porto Alegre: UFGRS, 2002.

ASSIS, Gláucia de Oliveira. Estar aqui, estar lá... uma cartografia da emigração valadarense para os EUA. In: REIS, Rossana R.; SALES, Teresa (Org.). Cenas do Brasil migrante. São Paulo: Boitempo, 1999. p. 125-166.

CARREIRA, António. Migraçôes nas ilhas de Cabo Verde. Lisboa: Universidade Nova de Lisboa, 1977.

DAMATTA, Roberto. Relativizando: uma introdução à antropologia social. Rio de Janeiro: Rocco, 2000.

DUARTE, Manuel. Caboverdianidade e africanidade... e outros textos. Mindelo, Cabo Verde: Spleen, 1999.

FERNANDES, Gabriel. A diluição da África: uma interpretação da saga identitária caboverdiana no panorama político (pós) colonial. Florianópolis: Editora da UFSC, 2002.

FRY, Peter. A persistência da raça: ensaios antropológicos sobre o Brasil e a África austral. Rio de Janeiro: Civilização Brasileira, 2005.

GIACOMINI, Sonia Maria. A alma da festa: família, etnicidade e projetos num clube social da Zona Norte do Rio de Janeiro - o Renascença Clube. Belo Horizonte: Editora UFMG; Rio de Janeiro: IUPERJ, 2006.

HANDING, Nina Corinne. "We are neither africans nor europeans": Cape Verdean students in Porto and their quest for social recognition. Bergen, 2001. 136 p. Tese (Doutorado) Departamento de Antropologia Social, University of Bergen, Noruega.

HERNANDEZ, Leila Maria Gonçalves Leite. Os filhos da terra do sol: a formação do estadonação em Cabo Verde. São Paulo: Summus, 2002.

HIRSCH, Olivia Nogueira; GIACOMINI, Sonia Maria. "Hoje eu me sinto africana": processos de construção de identidades em um grupo de estudantes cabo-verdianos no Rio de Janeiro. 2007. 227 p. (Dissertação de mestrado) —Departamento de Sociologia e Política, Pontifícia Universidade Católica do Rio de Janeiro, Rio de Janeiro.

JENKINS, Richard. Rethinking ethnicity: arguments and explorations. London: Sage Publications, 1997. 
LE BRETON, David. Adeus ao corpo: antropologia e sociedade. Campinas: Papirus, 2003.

LE BRETON, David. A sociologia do corpo. Petrópolis, RJ: Vozes, 2007.

LOBBAN, Richard A. Cape Verde: crioulo colony to independent nation. Colorado: Westview Press, 1995.

LOPES, Baltasar. Mesa redonda sobre o homem cabo-verdiano. Boletim Cabo Verde, Praia, ano 9, n. 99, 1957.

MARGOLIS, Maxine. Little Brazil: imigrantes brasileiros em Nova York. Campinas: Papirus, 1994.

PINHO, Patrícia de Santana. Reinvenções da África na Bahia. São Paulo: Annablume, 2004.

RODRIGUES, José Carlos. Tabu do corpo. Rio de Janeiro: Achiamé, 1979.

SANSONE, Livio. Negritude sem etnicidade: o local e o global nas relações raciais e na produção cultural negra do Brasil. Salvador: Edufba; Pallas, 2004.

SAYAD, Abdelmalek. A imigração ou os paradoxos da alteridade. São Paulo: Edusp, 1998.

THOMAZ, Omar Ribeiro. Do saber colonial ao luso-tropicalismo: "raça" e "nação" nas primeiras décadas do Salazarismo. In: MAIO, Marcos Chor e SANTOS, Ricardo Ventura (Org.). Raça, ciência e sociedade. Rio de Janeiro: Fiocruz/CCBB, 1996.

Recebido em 15 de julho de 2008 e aprovado em 26 de setembro de 2008. 